\title{
"TEORIA ECONÔMICA DO CRIME": DOS PRESSUPOSTOS ACADÊMICOS À EMPIRIA DO DIA A DIA NA VIDA DE EX PRESIDIÁRIOS DE SANTA MARIA RS
}

\section{Cezar Augusto Pereira dos Santos}

Mestre em Economia e Desenvolvimento pela Universidade Federal de Santa Maria (UFSM).

Endereço para contato: Rua 14 de agosto 1940 D, Bairro Esplanada - Chapecó - SC

CEP: 89812-435 - E-mail: cezarsantos1975@hotmail.com

\section{Dieison Lenon Casagrande}

Doutorando do Programa de Pós-Graduação em Economia da Universidade Federal de Pernambuco. Endereço para contato: Rua General Polidoro, 918 - Várzea - Recife - PE

CEP: 50740-050 - E-mail: dieisonlenon@yahoo.com.br

\section{Paulo Henrique de Oliveira Hoeckel}

Doutorando em Economia do Programa de Pós-Graduação em Economia da PUC/RS (PPGE/PUCRS)

Endereço para contato: Rua Prof. Cristiano Fischer, 2310 - Partenon - Porto Alegre - RS.

CEP: 91410-000 - E-mail: ph.hoeckel@ gmail.com

Recebido em 01 de fevereiro de 2016. Aceito em 29 de fevereiro de 2016.

\section{RESUMO}

A presente pesquisa apresenta os fundamentos de duas teorias que analisam os motivos que levam as pessoas a adotarem o caminho da ilegalidade penal (Teoria das Oportunidades e Neomarxista) em contraposto aos pressupostos da Teoria Econômica do Crime. A base da pesquisa é um diversificado referencial bibliográfico e as informações obtidas através das respostas de dezesseis homens e mulheres santamarienses a um formulário abrangendo desde o ambiente familiar no qual estavam inseridos quando cometeram os delitos, até questões comportamentais. Os resultados empíricos encontrados evidenciam que as pessoas que foram condenadas a penas de reclusão, pelo menos na amostra em análise, não se encaixam no perfil do "empresário" extremamente racional e maximizador de lucros - elemento chave da Teoria Econômica do Crime.

Palavras chave: Teoria Econômica do Crime; Teoria das Oportunidades; Teoria Neo-marxista;

\begin{abstract}
The present research presents the fundamentals of the two theories that analyze the motives that lead people to adopt the way of penal lawlessness (Theory of Opportunities and Neo-Marxist) in counterpoised the presuppositions of the Economic Crime Theory. The basis of the search it is a diversified bibliographic references and the information obtained through the answers of sixteen men and women santamarienses to a form spanning from the family environment in which they were inserted when committed the crimes, until behavioral questions. The found empirical results evidence that people who were sentenced to prison sentences, at least in the analyze sample, do not fit the profile of "entrepreneur" extremely rational, profit-maximizing - key element of Economic Theory of Crime.
\end{abstract}

Key-words: Economic Crime Theory; Theory of Opportunities; Neo-Marxist theory;

Econ. e Desenv., Santa Maria, vol. 27, n.2, p. 308 - 325, jul. - dez. 2015 RE\&D 


\section{INTRODUÇÃO}

Conforme Adam Smith (1996), a diferença de talentos naturais entre os indivíduos é muito menor do que costumeiramente "pensa" o senso comum. Ainda segundo este autor, a diferença entre as personalidades mais dispares ([ele utiliza como exemplo comparativo um filósofo e um carregador de feira], parece não provir tanto da natureza, mas antes do hábito, do costume, da educação ou formação.

Um fenômeno parecido também se dá entre os jovens cujas origens se encontram nos estratos de rendas mais baixas da sociedade. Por que, enquanto a grande maioria de tais indivíduos se mantém, durante toda a vida, no caminho da legalidade, uma parcela deles trilha o caminho da criminalidade e se mantém a margem da sociedade?

O presente trabalho aborda como objeto de análise homens e mulheres santamarienses que em um momento qualquer de sua existência migraram para o mundo da criminalidade (não necessariamente permanecendo neste caminho após o cumprimento da pena), levando em conta não só o aspecto econômico em suas vidas pré-crimes, mas também, os fatores familiares, educacionais e pessoais. A pesquisa está baseada no chamado método indutivo com afirmações singulares. Ou seja, a verdade de tais afirmações deve ser estabelecida com cuidado, pois se referem a um estado de coisas (no caso pessoas), num lugar específico, num tempo específico (CHALMERS, 1993). No que se refere ao método de procedimento, ressalta-se que para esta pesquisa foi utilizada uma combinação de procedimentos teórico-metodológicos:

- Levantamento de um referencial bibliográfico da problemática em foco, trabalhando temáticas vinculadas à criminalidade.

- Levantamento de dados por meio de um formulário contendo tanto questões fechadas quanto abertas abordando temas como aspecto familiar, educacional, econômico, relacionado aos crimes cometidos.

Em relação a esses dados, é importante destacar que a amostra de 16 indivíduos se deveu ao fato da Superintendência de Serviços Penitenciários (SUSEPE) não ter dado liberação para que o formulário fosse entregue aos reclusos do Presídio Regional de Santa Maria - RS. Com base nesta limitação, a decisão adotada foi coletar os dados através da busca por pessoas que já tivessem cumprido pena de reclusão e estivessem dispostas a colaborar com a pesquisa. A base de trabalho escolhida foi a pesquisa de Schaefer e Shikida (2001) sobre a economia do crime no qual analisaram uma amostra de vinte e uma pessoas.

O problema a ser respondido por este trabalho é: Por que as pessoas decidem cometer crimes de cunho econômico (por exemplo, furto, roubo e tráfico de drogas)? A hipótese aqui assumida é de que apenas os pressupostos da chamada "Teoria econômica do crime" não dão sustentabilidade empírica para explicar tal "decisão".

Além desta introdução o artigo conta com mais quatro seções. A temática da criminalidade sob o prisma teórico abordado em três teorias, que servem de suporte para a análise dos dados (Teoria Neo-marxista, Teoria Econômica do crime e Teoria das Oportunidades), é discutida na segunda seção. Na terceira seção são analisadas as informações obtidas e discutidos os pressupostos que embasam a teoria econômica do crime. Por fim, são apresentadas as considerações finais que sintetizam as análises realizadas durante a pesquisa.

\section{Revisão Teórica}

Conforme alguns pesquisadores do chamado campo das ciências sociais, existem três correntes vinculadas aos estudos econômicos que analisam a relação economia / crime. Uma destas correntes tem como base a teoria marxista (daí ser chamada por alguns de Teoria Neo-

Econ. e Desenv., Santa Maria, vol. 27, n.2, p. 308 - 325, jul. - dez. 2015 RE\&D 
marxista) e sugere que o aumento da criminalidade, principalmente a relacionada à ocorrência de delitos de cunho econômico, tem estreita relação com o desenvolvimento do modo de produção capitalista. Outra teoria, que tem o economista Gary Becker como seu principal expoente é a chamada Teoria Econômica do Crime, cujo pressuposto é o de que a tomada de decisão dos indivíduos em relação a cometer crimes que visem lucros financeiros é uma atividade ou setor da economia, como outro qualquer (SHAEFER e SHIKIDA, 2001).

Por fim, existe a chamada Teoria das Oportunidades que considera a existência prévia de pessoas com intenções criminosas e busca explicar, levando em conta os alvos disponíveis e o grau de proteção que os envolve, a probabilidade de que venham a ser ou não atacados (SAPORI e WANDERLEY, 2001).

$\mathrm{Na}$ sequiência são apresentadas, de forma um pouco mais detalhada, cada uma destas teorias.

\subsection{A Teoria Neo-marxista}

Esta corrente teórica que tem como principal referência Richard Quinney ${ }^{1}$, ao analisar o fenômeno da criminalidade o associa ao modo como se desenvolveu o processo capitalista de produção e seus reflexos sobre a coletividade social. Para se estudar o caráter criminoso, de acordo com esta linha de pensamento, é preciso levar em conta as contradições existentes no sistema capitalista (como por exemplo, alienação, desigualdade, concentração de renda, riqueza, pobreza, desemprego, subemprego, crises econômicas...), uma vez que estas contradições servem de base para que comportamentos anti-sociais se disseminem. Ou seja, por esta óptica, a questão criminal possui uma relação íntima com o caráter dual do sistema capitalista de produção, que de um lado promove desenvolvimento científico e tecnológico em busca de acumulação e concentração de capital, enquanto de outro, proporciona o aumento da miséria das massas trabalhadoras (SILVA, 2007).

A face atual do sistema capitalista de produção, de acordo com Cunha (2008), é reflexo de um fenômeno mundial que se desenvolve desde a segunda metade da década de 1970 - após a derrocada do processo que ficou conhecido como Estado de Bem-Estar Social ${ }^{2}$. Tal processo é denominado de Neoliberalismo. Este novo processo, de acordo com a visão Neo-marxista, busca se insurgir contra qualquer limitação estatal aos mecanismos de mercado - limitações estas, denunciadas como uma ameaça letal à liberdade tanto econômica, quanto política. Conforme este mesmo autor, as consequiências sociais da aplicação do Neoliberalismo nos países periféricos (entre eles o Brasil) têm sido catastróficas. Dentre estas conseqüências se destacam, por exemplo, as privatizações (final da década de 1980 e início da década de 1990), que geraram em seu processo demissões em massa, tanto no setor público quanto privado - o que fez com que grande parte desse contingente de trabalhadores migrasse para o mercado informal. Em contrapartida, como boa parte dos trabalhadores convive com o espectro do desemprego, grande número de desordens psicossociais tende a se manifestar. Em tal contexto,

\footnotetext{
${ }^{1}$ Sociólogo americano conhecido por suas críticas e abordagem filosófica da criminalidade e justiça social. Para conhecer melhor o trabalho de Quinney ver: QUINNEY, R. Criminology. Boston: Little Brown and Company, 1979.

2 Também conhecido como Welfarestate, pode ser compreendido como um conjunto de serviços e benefícios sociais de alcance universal promovidos pelo Estado, após o fim da Segunda Guerra Mundial, com o objetivo de garantir certa "harmonia" entre o avanço das forças de mercado e uma relativa estabilidade social, suprindo assim, as classes menos favorecidas economicamente de benefícios sociais capazes de proporcionar uma base minimamente aceitável de padrão de vida (GOMES, 2006).
}

RE\&D Econ. e Desenv., Santa Maria, vol. 27, n.2, p. 308 - 325, jul. - dez. 2015 
a reação de muitos indivíduos é adotar o comportamento marginal vindo a cometer atos delituosos.

Ou seja, segundo os pressupostos básicos da Teoria Neo-marxista, boa parte das pessoas, a mercê de eventos econômicos adversos, encontra-se, muitas vezes, impelida pelas forças das circunstâncias a adotar comportamentos criminosos. Ou seja, elas não fazem uma escolha arrazoada das opções disponíveis - simplesmente agem. Isto contraria a próxima Escola Teórica a ser analisada.

\subsection{A Teoria Econômica da Criminalidade}

O grande nome dentre os estudiosos da chamada análise econômica do comportamento criminal é, sem dúvida, o economista Gary Becker, ganhador do Nobel em Economia no ano de 1992 por sua explicação de tal comportamento utilizando a escolha individual sob incerteza. Conforme a teoria de Becker, um modelo "ótimo" de combate ao crime deveria incluir as seguintes relações individuais: o número de crimes, o custo financeiro de tais crimes, o percentual desses crimes que são punidos de forma efetiva, o percentual de prisões e condenações, os gastos com efetivos policiais, os gastos com o sistema judicial e carcerário. Assim, tudo o mais constante, segundo os pressupostos de Becker, um aumento na probabilidade de punição efetiva de um cidadão deve reduzir substancialmente o potencial número de delitos que ele venha a cometer (BRITTO, 1999).

Segundo tal linha de pesquisa, o indivíduo que comete um crime de cunho econômico pode ser considerado uma espécie de "empresário", e como um empresário de qualquer ramo de atividade econômica, seu objetivo primordial vem a ser o lucro obtenível em cada empreitada. Porém, em tal "mercado" (criminoso), existe um grande risco deste individuo vir a sofrer algum tipo de sanção (multa, prisão, ou talvez até mesmo a morte). Além disso, para alguns estudiosos, tais atividades convivem em muitos casos de forma implícita com o princípio hedonista ${ }^{3}$ (SHAEFER e SHIKIDA, 2001).

Becker (1968) parte do pressuposto de que o indivíduo criminoso, conforme seu grau de aversão ao risco decide quanto de seu tempo alocar entre uma atividade econômica legal ou ilegal. Assim, se sua utilidade esperada ao cometer um ato delituoso for maior que a utilidade que poderia vir a obter no mercado legal, ele opta por cometer o delito ${ }^{4}$.

A teoria econômica do crime, conforme os pressupostos e modelos acima analisados, em seus primeiros estudos (Becker) partiu de um arcabouço teórico utilitarista em direção a modelos que incorporam questões e variáveis sociológicas, assim como a próxima escola a ser analisada.

\subsection{Teoria das Oportunidades}

Os defensores desta escola de pensamento partem do pressuposto de que a ocorrência de crimes econômicos - furtos, roubos, tráfico de drogas e armas, por exemplo - está ligada a uma oportunidade que se revela disponível diante do potencial criminoso. Eles classificam a

\footnotetext{
3 Também chamado de princípio utilitarista de Jeremy Bentham. Este princípio afirma que, se por um lado, os homens buscam para si o maior prazer e felicidade possível, por outro, desejam reduzir e prevenir a sua dor. "Nature has placed mankind under the governance of two sovereign masters; pain and pleasure" (BENTHAM, 1907, p. 4).

4 Os modelos de portfólio apresentam como pressuposto o fato de que a pessoa leva em conta as diferentes oportunidades disponíveis no sistema econômico, e após avaliar o risco decide o quanto investir no setor legal e ilegal tendo estimativas prévias dos lucros em cada um desses setores (CARRERA-FERNANDEZ e PEREIRA, 2000).
}

Econ. e Desenv., Santa Maria, vol. 27, n.2, p. 308 - 325, jul. - dez. 2015 RE\&D 
ocorrência deste tipo de crime como algo "normal", e não necessariamente uma patologia cujo resultado esteja intrinsecamente relacionado com diferenças de personalidade entre as pessoas criminosos e não criminosos (COHEN E FELSON, 1979).

Polemicamente, Cohen e Felson (1979) argumentam que se a oportunidade disponível é capaz de gerar um retorno financeiro suficientemente vantajoso e o alvo não está suficientemente protegido, fatalmente o delito irá ocorrer. Ou seja, a partir deste ponto de vista, é possível inferir que o delito não prescinde de criminosos condenados com antecedentes, os quais revelem uma pré-disposição para o crime. O crime precisa apenas de uma oportunidade qualquer cidadão poderia, potencialmente, vir a cometê-lo.

Ampliando sua análise, Cohen e Felson (1980) cunharam o termo "efeito oportunidade sobre o crime", termo este ligado às justificativas do por que ocorrem os crimes contra o patrimônio. Segundo tais pesquisadores, tudo o mais constante, uma diminuição na densidade populacional em regiões basicamente residenciais leva a um aumento nas oportunidades criminais e, assim, a um aumento nas ocorrências de tais tipos de crime.

A idéia básica subjacente a argumentação de Cohen e Felson, conforme Britto (1999), é que o percentual de crimes patrimoniais está intimamente conectado com as facilidades encontradas nas circunstâncias que se apresentam aos eventuais criminosos. Logo, acompanhando tal raciocínio, os crimes contra a propriedade requerem, ao mesmo tempo, a conjugação de três elementos: a) a existência de um ou mais indivíduos motivados a cometer o crime; b) a existência de pelo menos um alvo disponível para cometer o delito e c) a inexistência de segurança efetiva em relação a tais alvos.

\section{Análise dos formulários: teste das teorias sobre a relação economia-crime}

\subsection{Gênero, juventude e crime}

No Brasil, os dados que tratam da criminalidade feminina são poucos e pouco reveladores da real dimensão deste fenômeno social. Isto ocorre, talvez pela constatação de que a participação feminina em relação à criminalidade total seja, percentualmente, pouco significativa quando comparada à masculina. Segundo o quadro 01, em geral, o percentual da criminalidade feminina em relação à criminalidade total não ultrapassa dez por cento (FRINHANI e SOUZA, 2005).

Porém, tal visão precisa, urgentemente, ser repensada, uma vez que a criminalidade feminina, no decorrer dos últimos anos, tem crescido em termos percentuais bem mais do que a criminalidade masculina - considerando o número total de pessoas reclusas. Por considerar tal problemática, na presente pesquisa são analisadas as semelhanças e diferenças nas respostas ao formulário dadas por homens e mulheres. Dentre as pessoas que responderam o formulário, $81 \%$ delas são do gênero masculino (para o trabalho o percentual de mulheres de quase vinte por cento é bem maior do que os cerca de cinco por cento, que são a média nacional de mulheres reclusas em relação ao número total de indivíduos presos).

Tabela 01 - População carcerária no Brasil por gênero - 2000 e 2010

RE\&D Econ. e Desenv., Santa Maria, vol. 27, n.2, p. 308 - 325, jul. - dez. 2015 


\begin{tabular}{l|l|l|l|l|l}
\hline & \multicolumn{2}{|c|}{$\begin{array}{c}\text { NO SISTEMA } \\
\text { PRISIONAL* }\end{array}$} & \multicolumn{2}{l}{ POPULAÇÃO TOTAL** } & $\begin{array}{c}\text { Aumento } \\
(\%)\end{array}$ \\
\hline & 2000 & 2010 & 2000 & 2010 & \\
\hline $\begin{array}{l}\text { Homens } \\
(\mathrm{A})\end{array}$ & 130.365 & 417.517 & 83.602 .317 & 93.406 .990 & 320,27 \\
\hline $\begin{array}{l}\text { Mulheres } \\
(\mathrm{B})\end{array}$ & 5.345 & 28.188 & 86.270 .539 & 97.348 .809 & 520,37 \\
\hline $\begin{array}{l}\text { Total (C) } \\
\text { [B / C] }\end{array}$ & 135.710 & 445.705 & 169.872 .856 & 190.755 .799 & \\
\hline
\end{tabular}

FONTES: DEPEN. * Regimes de condenação: aberto, semi-aberto; fechado; medidas de segurança. ** IBGE.

No que se refere à idade e estado civil, enquanto $66 \%$ (sessenta e três por cento) do total das pessoas pesquisadas eram solteiros (as) na época dos delitos e cinquenta por cento deste total foram presos (as) entre os dezoito e vinte anos de idade, apenas $25 \%$ deles (as) tinha mais de vinte e cinco anos - e conforme seus relatos, muitos deles (as) já vinham cometendo delitos desde a adolescência.

Ou seja, com base nas informações acima, em uma primeira análise, pode-se ter uma idéia do quão jovem (e imaturos) tendem a ser os indivíduos ao adentrar pela primeira vez nas estatísticas do sistema carcerário brasileiro.

\subsection{Contexto ambiental/familiar e criminalidade}

Conforme Oliveira (2005), inicialmente, o ato de cometer um crime, ou seja, violar uma regra socialmente aceita pode ou não envolver um custo moral. Assim, mesmo que do ponto de vista financeiro a melhor decisão pareça ser a opção pelo mercado ilícito, a inclusão de um custo moral no modelo pode criar a barreira necessária para a entrada neste mercado. Com isso, surge então a necessidade de se entender como se processa no indivíduo a construção deste julgamento.

Ao longo da vida os indivíduos vão construindo relações que começam inicialmente com seus familiares, passando pela fase da adolescência, e se estendem até a sua inserção na sociedade na fase adulta. Cada indivíduo se desenvolve em um determinado contexto. Este contexto, ou ambiente (ou infra-estrutura familiar e sócio-ambiental), é fundamental no processo de construção do julgamento moral, e por conseqüência, na decisão de cometer um crime ou não. Ou seja, o ambiente influencia o desenvolvimento individual (OLIVEIRA, 2005).

Com o objetivo de descobrir até que ponto a infra-estrutura social (como acesso a boas escolas, bairros com maior número de opções de lazer, cursos profissionalizantes) influencia a entrada na criminalidade, segundo a ótica dos sujeitos que já cumpriram pena de reclusão, foi lhes feita a seguinte pergunta: a falta de uma estrutura social (acesso a melhores escolas, bairro mais seguro, acesso a melhores oportunidades de emprego) capaz de lhe proporcionar uma vida mais desenvolvida economicamente influenciou seu envolvimento com a criminalidade?

As respostas para tal pergunta foram surpreendentes, pois a priori, esperava-se que a grande maioria fosse apontar que a infra-estrutura social teve bastante influência no fato de ter adotado o caminho da criminalidade. Porém, para cinqüenta por cento dos indivíduos

Econ. e Desenv., Santa Maria, vol. 27, n.2, p. 308 - 325, jul. - dez. 2015 RE\&D 
entrevistados o acesso a uma escola melhor e melhores oportunidades de emprego não foram fatores preponderantes. Em relação a tal resposta, um dos entrevistados apresentou uma argumentação bastante surpreendente. Segundo ele:

"muita gente, inclusive eu, não gosta mesmo de estudar e trabalhar. Mesmo tendo melhores oportunidades de emprego, o sujeito já gosta de pegar o que é dos outros. Não vai se emendar".

Por outro lado, para trinta e oito por cento dos que responderam ao formulário, o fato de não ter tido acesso a melhores oportunidades, tanto escolares quanto no mercado de trabalho, tiveram peso decisivo em sua trajetória criminal.

"O filho do pobre quer ir bem becado pro colégio, não quer passar vergonha. $\mathrm{Na}$ adolescência, vê o pobre do pai se matando, de sol a sol, e sem adquirir nada. O guri quer andar de motinho, fazer grau. Trabalhando de servente fica difícil, né? Numa lança, às vezes pode comprar a moto numa pegada. Vai trabalhar de servente? È claro que infra-estrutura social influencia”.

De acordo com Hasson e Meleiro, (2003), em relação à questão familiar, é comprovado pela ciência que é através do núcleo familiar que as crianças obtêm sua base moral, e é do ensinamento obtido, principalmente dos pais que o indivíduo constrói seu caráter, uma vez que é no seio familiar que a criança aprende as primeiras noções de educação, regras e limites que servirão de parâmetros para seus futuros valores éticos e morais. Assim, surgiu o seguinte questionamento: até que ponto as atitudes dos indivíduos que contrariam as normas legais da sociedade são reflexos da educação e dos exemplos herdados do seio familiar? Ou seja, como era formada sua base familiar no período pré-crime.

Quanto ao aspecto de como era formado o núcleo familiar, cerca de 55\% dos respondentes afirmaram que moravam, na época em que foram presos, com pai, mãe e irmãos. Tal resultado já era esperado, pois como boa parte dessas pessoas ao serem presas era bastante jovem, nada mais natural que morassem com os pais. Além disso, em um quarto das respostas, as pessoas entrevistadas afirmaram morarem junto com seus filhos. Como foi dada a opção de mais de uma resposta dentre as possíveis no formulário, pode se perceber que boa parte das pessoas em análise, na época do cometimento dos delitos, morava com os pais. Porém, já possuía filhos.

Até aqui temos o seguinte quadro: pessoas bastante jovens, podendo se deduzir daí, que também imaturos (já que é natural a imaturidade em tal fase da vida), morando com os pais. Porém, muitos por sua vez, também já eram pais e mães. Em alguns dos casos analisados, tais pessoas relataram ser filhos de pais e mães bastante jovens e, por sua vez, estes jovens vieram a se tornar pais e mães também precocemente.

Quanto à questão da paternidade, o presente trabalho buscou descobrir a importância da presença do pai no seio da família. A necessidade de questionamento se deu a partir do fato de que, quando inquiridos sobre o fato de ter pai em casa quando adolescentes, muitos dos entrevistados afirmaram que sim. Porém, quando confrontados com a seguinte pergunta: Teve pai presente de forma efetiva na adolescência, as respostas se tornavam bastante diferentes (ver figura 1).

RE\&D Econ. e Desenv., Santa Maria, vol. 27, n.2, p. 308 - 325, jul. - dez. 2015 


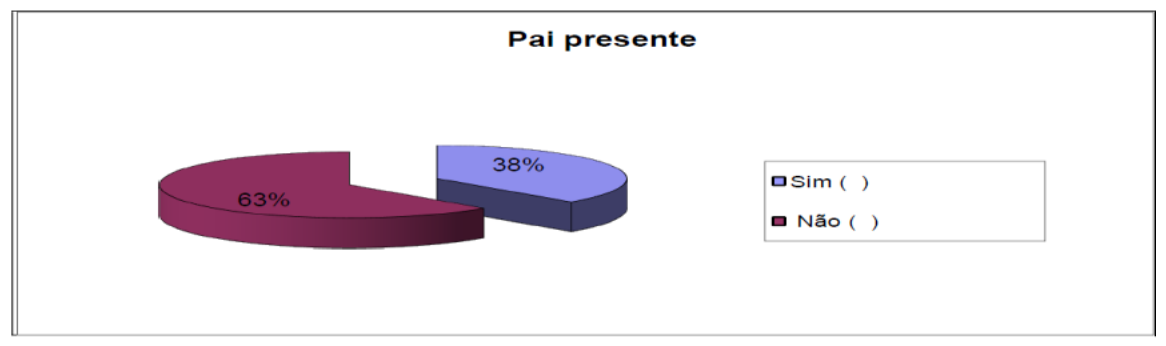

Figura 1: Pai presente de forma efetiva no lar. Fonte: Elaboração própria.

Em alguns casos, o pai embora fisicamente presente e cumprindo o papel de provedor do lar não tinha um contato efetivamente afetivo com os filhos. Para tais pais, seu papel era, como se pode perceber pelas respostas, apenas o de trazer o salário para casa.

\begin{abstract}
"trabalhava com o velho que era dono de uma microempresa de construção. Ganhava uma grana que mal dava para sair no fim de semana. O coroa dizia que era o que dava para me arranjar, por que estava guardando para o nosso futuro. Eu queria mais grana. Só quando ele morreu fui saber que ele deixou duas casas para cada filho. Hoje, após cumprir a pena moro em uma e alugo a outra. Mas, carinho, levar pra jogar bola, ajudar com os temas, isto ele nunca fez. Tava sempre correndo".
\end{abstract}

Porém, em outros casos a situação era bastante pior. Pela conversa de alguns entrevistados, pode-se perceber que o "pai" (ou na falta deste o padrasto) teve um papel direto na formação criminosa do filho. Em diferentes entrevistas foi relatado o alcoolismo e o uso de drogas ilícitas por parte dos pais e, até mesmo a influencia do responsável pela formação moral do jovem para que o mesmo cometesse delitos.

“o pai era bêbado, desses de cair na rua, a mãe bebia nos bares e dava show. Tanto o pai quanto a mãe eram daqueles de cair na sarjeta. Não tinham moral nenhuma pra querer mandar em mim e nos manos".

"quando era garoto, morava com o meu padrasto, o pai mesmo, nunca soube quem era. O meu padrasto que era eletricista, dizia: - se quer comer da minha comida, tem que trabalhar. Vagabundo comigo não se cria. Só que o próprio padrasto quando fazia um orçamento, pedia, por exemplo, mais rolos de fios do que o necessário para a obra. Depois, ele me chamava e dizia: - coloca esses rolos na tua mochila e leva lá no fulano e me traz o dinheiro. Ou seja, eu não podia ser vagabundo, mas ladrão podia”.

Assim, conforme as falas dos entrevistados e a figura 2 é possível intuir que tal carência é bastante influente nas decisões tomadas por um sujeito ainda em formação. Claro, que com isto, não se está querendo afirmar que a falta de uma presença paterna de forma efetiva leve, necessariamente, o individuo a trilhar o caminho da criminalidade. Mas, apenas, que inegável a importância de tal presença na formação do caráter de qualquer pessoa.

\title{
3.5 Educação e criminalidade
}

Econ. e Desenv., Santa Maria, vol. 27, n.2, p. 308 - 325, jul. - dez. 2015 RE\&D 
Conforme Abramovay (2008), salvo raras exceções, em geral, os históricos dos indivíduos que cumprem pena no sistema prisional são de expulsão e fracasso escolar. Para tal autora, a escola deve ser um espaço de construção de saberes, de convivência e socialização. Porém, a padronização de nosso sistema escolar acolhe e reforça as desigualdades entre as classes sociais e torna mais visível o bloqueio do sistema às crianças e jovens de classes de rendas mais baixas.

Muitas vezes, a escola, a exclusão e a violência encontram-se perigosamente correlacionadas no histórico de vida de muitos jovens. Pois, o sistema educacional brasileiro ao mesmo tempo em que, em comparação com outros períodos de nossa história, amplia o oferecimento de vagas em todos os níveis escolares, através de múltiplos caminhos e mecanismos, produz também um processo de seletividade no ambiente escolar que se reflete de forma direta sobre as camadas menos favorecidas economicamente da população. Esta seletividade encontra-se ligada tanto a fatores estruturais da organização do sistema de ensino (necessidade do jovem de freqüentar um bom curso de Inglês, Informática, curso pré-vestibular) como ao sistema social como um todo - busca do jovem em andar com as roupas da moda, possuir as últimas novidades tecnológicas, enfim, sentir-se aceito (ARAÚJO e CARVALHO, 2007).

Porém, para muitos garotos e garotas, este sentir-se aceito nunca acontece, pois muitas vezes acabam rotulados, tanto por alunos como por professores como relapsos, irrequietos, voadores, relaxados, preguiçosos, bandidinhos, enfim, com uma série de adjetivos depreciativos. O problema, é que não é necessário muito tempo, para que a própria criança passe a se crer portadoras de tais características. Ou seja, a profecia acaba se auto cumprindo (ZALUAR, 1997).

Em relação à escolaridade dos indivíduos analisados, em quase todos, verificou-se um histórico de abandono escolar em uma idade bastante tenra e um grau de escolaridade bastante baixo. Ou seja, mais de noventa por cento dos respondentes não concluíram o ensino médio e, quase cinquenta por cento deles, sequer concluiu o ensino fundamental.

Conforme as entrevistas é possível observar um interessante paradoxo. Para muitos, ao responderem sobre o que achavam que deveria ser feito para diminuir os índices de criminalidade, responderam que deveria ser dado mais acesso à educação, mais tempo de permanência na escola durante o dia, mais acesso a cursos profissionalizantes. Porém, quando perguntados se tiveram acesso a escola, responderam que sim. O problema, segundo eles, é que a escola era chata, se sentiam desmoralizados por não terem o que alguns outros alunos possuíam (boas roupas, tênis de marca). Além disso, a rua era bacana e não tinham ninguém em casa para controlá-los.

Conforme as informações levantadas, o perfil, por assim dizer, pré-crime dos indivíduos que responderam ao formulário, está bastante distante do sujeito com capacidade de analisar de maneira friamente racional as diferentes alternativas que se lhe apresentavam antes de adotar $o$ caminho da marginalidade.

RE\&D Econ. e Desenv., Santa Maria, vol. 27, n.2, p. 308 - 325, jul. - dez. 2015 


\section{Dados relativos ao crime cometido \& dados relativos a fatores econômicos}

\subsection{Tipos de crimes cometidos e os motivos para cometê-los}

Com o objetivo de descobrir os motivos, segundo a percepção dos atores envolvidos na realização dos delitos, que os levaram a transgredir as normas legais, foi-lhes perguntado quais os motivos (podendo citar quantos desejassem) que os levaram a realizar os delitos.

Com base nas respostas ao formulário, setenta cinco por cento dos respondentes foram presos por tráfico de drogas e os outros vinte e cinco por cento por assaltos e/ou furtos. Segundo eles, os principais motivos que os levaram a cometer os delitos (tabela 4) foram para obter status junto ao grupo com o qual andavam (tal resposta apareceu em oito dos formulários), a busca por ganho fácil, e sustentar o vício em drogas ilícitas. O que chama atenção é que nas respostas das mulheres, um dos motivos citados (por todas) é sustentar a família. Além disso, tais mulheres acabaram entrando no caminho da criminalidade por influência direta (acompanhar o namorado na busca da droga em outro estado) ou indireta (marido foi preso e a mulher assumiu a venda da droga) dos companheiros.

Tabela 02 - Motivos que o (a) levaram a cometer os delitos

\begin{tabular}{l|c}
\hline \multicolumn{1}{c|}{ MOTIVOS } & FREQUÊNCIA \\
\hline $\begin{array}{l}\text { Obter status junto ao grupo e influência de } \\
\text { Amigos }\end{array}$ & 6 \\
\hline Ganho fácil & 6 \\
\hline Sustentar o vício em drogas ilícitas & 5 \\
\hline Cobiça e ambição & 5 \\
\hline Sustentar a família & 2 \\
\hline Efeito do uso de álcool & \\
\hline
\end{tabular}

Fonte: Elaboração própria.

Também, é notável a correlação encontrada entre o uso de drogas ilícitas (maconha e cocaína) e a adoção do caminho da criminalidade. Pois, quase sessenta por cento das pessoas que responderam ao formulário afirmaram fazer uso de drogas ilícitas na época em que cometeram os delitos pelos quais acabaram presos. Além disso, dentre os cinqüienta por cento que responderam serem usuários de drogas ilícitas, vinte e cinco por cento deles usavam apenas cocaína, treze por cento eram usuários de maconha e dezenove por cento faziam uso dois tipos de entorpecentes.

Entre os homens, com relação aos motivos que os levaram a cometer os delitos predominou a vontade de obter status no grupo de indivíduos com o qual se relacionava. Porém, entre as mulheres o sustento da família foi o motivo que mais pesou em sua decisão. Em muitos casos, a iniciação criminal dessas mulheres se deu através do convívio com maridos e companheiros já envolvidos com a criminalidade. Além disso, foi bastante alta a incidência do uso de drogas ilícitas durante o cometimento dos delitos pelos quais as pessoas que responderam ao formulário foram presas.

4.2 Noção do risco envolvido na decisão de cometer um crime

Econ. e Desenv., Santa Maria, vol. 27, n.2, p. 308 - 325, jul. - dez. 2015 RE\&D 
Conforme analisado anteriormente, no modelo econômico de escolha racional, o sujeito que comete um crime que visa obter uma vantagem financeira pode ser considerado um agente econômico; logo, ao contemplar a possibilidade de envolvimento em um ato ilícito, tal sujeito responde a incentivos sócio-econômicos, a partir da avaliação racional entre ganhos e perdas esperadas, advindos das atividades ilícita vis-à-vis o ganho alternativo no mercado legal levando em conta sua aversão ou não aos riscos envolvidos na atividade ilegal (FRONER, 2008).

$\mathrm{O}$ risco pode ser definido como uma estimativa do grau de incerteza que se tem com respeito à realização de resultados futuros desejados. Ou seja, o risco tem a ver com uma situação na qual seu desdobramento pode originar múltiplos resultados possível, mas cujas probabilidades de cada resultado são conhecidas ou podem ser estimadas. Assim, através da análise probabilística, é possível calcular o valor esperado ${ }^{5}$ e a variabilidade ${ }^{6}$ dos possíveis resultados dos eventos para que o sujeito tomador de decisões possa descrever e comparar escolhas de risco (PINDICK e RUBINFELD, 2002).

Seguindo tal raciocínio, de acordo com Delassopa (2008), a análise de risco deve levar em conta a probabilidade de que um evento não desejado aconteça provocando um dano em um cenário ou tempo futuro realizando possível cálculo de uma expectativa de valor para essa probabilidade, cálculo este, que leva em conta, em cada caso, a utilidade ${ }^{7}$ esperada. Com base nisto, em relação ao modo como se viam frente ao risco inerente ao fato de adotarem o caminho da criminalidade foi feita, aos indivíduos da amostra, a seguinte pergunta: Você tinha noção do risco envolvido ao cometer os delitos pelos quais foi preso?

Dentre as pessoas que responderam ao formulário, sessenta e nove por cento delas afirmou ter noção do risco envolvido em sua atividade criminosa (porém, cerca de trinta e um por cento sequer tinha noção do risco que corria).

Outra questão analisada se refere ao comportamento individual quanto a disposição em assumir riscos. Certas pessoas, por exemplo, demonstram extrema aversão ao risco, algumas são mais dispostas a correr riscos, enquanto outras se mostram neutras ao risco. Conforme os pressupostos da teoria microeconômica, um sujeito avesso ao risco é aquele que prefere manter uma renda garantida a um emprego de risco, no qual a renda esperada seja a mesma. Para tais pessoas, as perdas são mais importantes (em termos de variação de utilidade) dos que os ganhos, assim, para tais indivíduos um retorno mais alto é exigido em função do aumento do risco. Já o indivíduo neutro ao risco, é aquele para o qual é indiferente o recebimento de uma renda garantida e o recebimento de uma renda incerta que apresente o mesmo valor da renda esperada. A utilidade marginal da renda é constante para tais pessoas. Ou seja, para tais sujeitos, não haveria nenhuma variação de retorno exigida em razão de uma variação nos níveis de risco. No outro extremo, se um sujeito prefere uma renda incerta a uma certa, mesmo que o valor esperado da renda incerta seja menor do que o valor da certa, tal sujeito pode ser considerado

\footnotetext{
${ }^{5} \mathrm{O}$ valor esperado associado a um evento incerto corresponde a uma média ponderada dos payoffs - valor do retorno, positivo ou negativo, associado a um resultado possível de ocorrer - de todos os possíveis resultados, sendo a probabilidade de cada resultado vir a ocorrer utilizadas com seu respectivo peso. Ou seja, o valor esperado mede a tendência central, o payoff que, na média, deve-se esperar que ocorra (PINDICK e RUBINFELD, 2002).

${ }^{6}$ Variabilidade é o grau de diferença entre resultados possíveis em situações incertas. Se, por exemplo, o indivíduo se encontra frente à decisão de escolher entre dois empregos diferentes, no qual o rendimento esperado é o mesmo, mas, a variabilidade dos payoffs possíveis é diferente para os dois empregos, aquele que apresentar maior diferença (positivas ou negativas) entre os payoffs efetivos e esperados (chamados desvios) será o de maior risco (PINDICK e RUBINFELD, 2002).

7 "Utilidade se refere ao valor numérico que representa a satisfação que o consumidor obtém de uma cesta de mercado" (PINDICK e RUBINFELD, 2002, pp 73).
} 
com amante do risco. Os criminalistas descrevem certos criminosos como amantes do risco, pois cometem delitos com grandes possibilidades de virem a ser descobertos e presos (PINDICK e RUBINFELD, 2002).

Com base no exposto acima, em relação ao modo como se viam frente ao risco inerente ao fato de adotarem o caminho da criminalidade, foi feita, ainda, aos indivíduos da amostra, a seguinte pergunta: ao cometer os crimes, como se via frente às situações de risco? Cinqüenta por cento dos respondentes afirmaram que na época eram avessos ao risco e trinta e um por cento afirmaram que não pensavam muito sobre o assunto. Esta resposta derruba o mito de que muitos dos indivíduos que cometem crimes têm certo gosto pelo risco (amante do risco).

Outra questão importante a ser levantada é que, com base nos pressupostos da Microeconomia e da Teoria Econômica do Crime de Gary Becker, o sujeito que comete crimes visando o lucro financeiro pode ser considerado como o tradicional Homo Economicus ${ }^{8}$. Ou seja, um agente econômico extremamente racional, o qual se guia unicamente pela busca da maximização de sua utilidade esperada levando em conta todas as informações disponíveis e analisando friamente os diferentes caminhos que se lhes apresentam (SCOTTI, 2007).

Com o intuito de verificar empiricamente se tais pressupostos são válidos, foram feitas uma série de perguntas, como por exemplo, se ao cometer os delitos os sujeitos analisavam a diferença de renda que poderiam obter com o crime em comparação com o que poderiam receber trabalhando no mercado legal ou se agiam por impulso (Figura 3).

Com base nas respostas, pelo menos para a amostra em questão, é derrubado o argumento de que o sujeito que comete delitos que busquem um ganho financeiro pode ser considerado um "empresário" extremamente racional, o qual se guia levando em conta todas as informações disponíveis e que através de uma racionalidade fria escolhe entre os diferentes caminhos possíveis o que melhor lhe convém. Por exemplo, dentre os indivíduos entrevistados, ocorreram casos em que o sujeito assaltou um verdureiro e roubou apenas a carroça, na qual foi encontrado dormindo. Ou, casos em que o sujeito traficava apenas para poder usar a droga, não tendo sequer uma televisão dentro de casa.

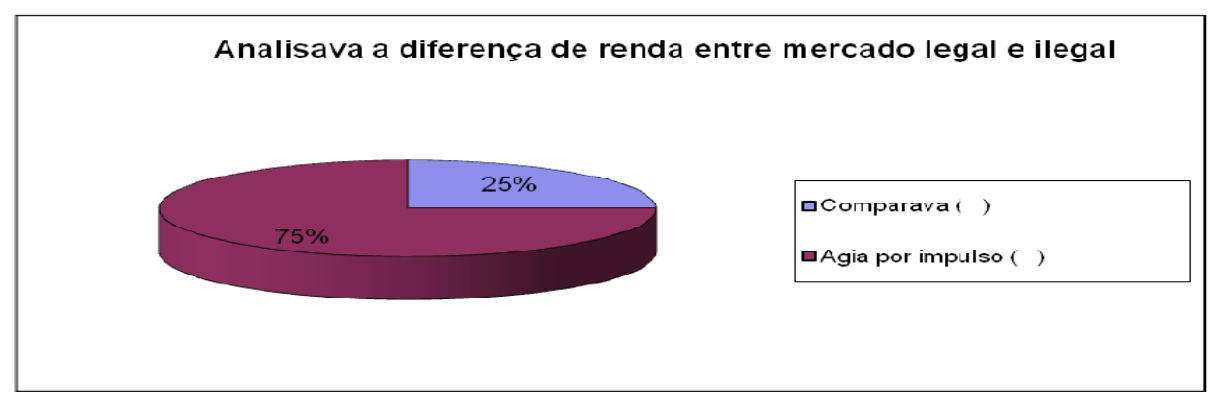

Figura 3 - Análise da diferença de renda entre mercado legal e ilegal. Fonte: Elaboração própria.

Em contraponto à argumentação da Teoria Econômica do Crime, a Teoria das Oportunidades, como já antes afirmado, parte do pressuposto de que a ocorrência de crimes econômicos está ligada a uma oportunidade que se revela disponível diante do potencial criminoso. Ou seja, se é fácil o acesso aos meios para que o crime seja cometido, um percentual

\footnotetext{
${ }^{8}$ O Homo Economicus seria o sujeito motivado exclusivamente por razões econômicas, preocupado em termos imediatos em obter o máximo de lucro com o mínimo de sacrifício. Tal individuo, agiria racionalmente com o objetivo de maximizar sua riqueza. Seria um sujeito hedonista, isto é, partidário da doutrina que considera que o prazer individual e imediato é o único bem possível, princípio e fim da vida moral (COSTA, 2009).
}

Econ. e Desenv., Santa Maria, vol. 27, n.2, p. 308 - 325, jul. - dez. 2015 RE\&D 
de indivíduos, em comparação a uma situação de maior dificuldade, irá cometê-lo. Assim, quando perguntado aos indivíduos que responderam ao formulário se o acesso aos meios para cometer os delitos eram fáceis, noventa e quatro por cento deles afirmaram que sim. Tal resposta não surpreende, pois na periferia de Santa Maria, possuindo dinheiro, é extremamente fácil a obtenção de armas e/ou drogas.

Tal resultado corrobora o pressuposto da Teoria das Oportunidades de que quanto maior a facilidade disponível, maior a probabilidade de que o crime aconteça. Outro pressuposto da Teoria das Oportunidades é de que os crimes contra a propriedade e o tráfico de drogas requerem, ao mesmo tempo, a conjugação de três elementos: a) a existência de um ou mais indivíduos motivados a cometer o crime; b) a existência de pelo menos um alvo disponível para cometer o delito e c) a inexistência de segurança efetiva em relação a tais alvos. Ou seja, partindo de tal pressuposto, uma maior dificuldade, gerando assim maior custo de oportunidade, deve levar a uma diminuição nos índices de tais crimes. Com o objetivo de verificar tal relação, foi abordado tal assunto no formulário. Segundo os indivíduos analisados, cerca de setenta por cento deles cometeriam os crimes que cometeram se fosse lucrativo, mesmo envolvendo um grau maior de dificuldade.

\subsection{Emprego e inserção social}

Em países como o Brasil, em que grande parte dos salários é aviltante e a qualidade do trabalho precária (trabalho informal, subemprego, ausência de garantias trabalhistas, etc.), o universo dos criminosos se confunde parcialmente com o universo dos trabalhadores. Ainda segundo este autor, os efeitos do desemprego sobre a criminalidade não são imediatos. Ninguém, a não ser um sujeito dotado de transtornos psicológicos, perde o emprego num dia e torna-se um criminoso no dia seguinte. O recém desempregado, em geral, tenta obter uma nova colocação no mercado de trabalho durante certo tempo. No caso de não obtê-la tenta recorrer às economias pessoais, ao salário desemprego, à ajuda de parentes e amigos, à informalidade, etc. Somente depois de repetidas tentativas frustradas de se colocar novamente no mercado de trabalho legal ou quando as demais estratégias de sobrevivência se esgotam, é que o crime passa a ser uma alternativa levada em consideração (KHAN, 2001).

Em relação ao fato de estar ou não empregado na época em que cometeu o crime, cerca de sessenta e cinco por cento dos indivíduos que responderam ao formulário estavam desempregados. Porém, tal percentual precisa ser analisado com cuidado. Pois, conforme alguns entrevistados, principalmente os envolvidos na venda de drogas, eles não procuravam emprego, já que ganhavam o suficiente para se prover através da criminalidade. Quanto aos trinta e cinco por cento que estavam empregados e mesmo assim cometeram delitos, o dinheiro obtido na ilegalidade servia para complementar a renda obtida no emprego legal. Além disso, o fato de possuírem um emprego de carteira assinada servia para disfarçar a vida dupla que levavam.

Porém, nas respostas em relação à seguinte pergunta: até que ponto acredita que o desemprego e a concentração de renda influenciam a entrada de alguém no mundo do crime a maioria (cinquienta e seis por cento) respondeu que tais fatores influenciam de maneira decisiva no fato de um sujeito adotar o caminho da criminalidade.

Tal resposta, corrobora os pressupostos da Teoria Neo-marxista. Ou seja, para cerca de sessenta por cento dos indivíduos analisados as contradições existentes no sistema capitalista (alienação, desigualdade, concentração de renda, riqueza, pobreza, desemprego, subemprego, crises econômicas...) servem de base para a disseminação de comportamentos anti-sociais. Mas, é preciso atentar para o fato de que para cerca de quarenta por cento dos que responderam ao

RE\&D Econ. e Desenv., Santa Maria, vol. 27, n.2, p. 308 - 325, jul. - dez. 2015 
formulário, o desemprego e a concentração de renda tem pouca ou nenhuma influência sobre a entrada de alguém no mundo crime.

Em algumas respostas os respondentes se contradizem completamente, pois respondem em uma questão que o desemprego e a concentração de renda não influenciam a entrada de alguém para o mundo do crime. Porém, quando perguntados sobre o que deveria ser feito para diminuir os índices de criminalidade, as mesmas pessoas afirmam que:

\begin{abstract}
"deveria existir mais oportunidades de emprego".
"talvez se os salários fossem melhores, os riscos de ficar preso não valeriam a pena".

"quando eu fui preso, saiu em tudo que foi jornal. Afirmaram que eu era um dos maiores traficantes de Santa Maria. Como eu ia arrumar emprego depois da pena. Sorte que montei um barzinho em casa e a mulher trabalha. Assim dá pra se virar".
\end{abstract}

Ou seja, mesmo quando as pessoas afirmam que o desemprego e a concentração de renda não influenciam a entrada de alguém para o mundo do crime, fica implícita em sua conversa a importância que há em um sujeito possuir um emprego. Sendo assim, é possível afirmar que os pressupostos da Teoria Neo-marxista são importantes para explicar o fenômeno da criminalidade.

\title{
4.4 Retorno financeiro dos delitos cometidos
}

Quanto ao fato do retorno financeiro da ação criminosa, se o sujeito que adota o caminho da ilegalidade pode ser visto como um "empresário", é de se esperar que tal indivíduo obtenha lucros com seu empreendimento, ou mude de ramo. Conforme as respostas do formulário, diferentemente do que imagina o senso comum, os traficantes, pelo menos os pequenos, que são os que acabam presos, muitas vezes moram em casas alugadas em bairros pobres, dirigem carros usados e em péssimas condições. Na maioria dos casos, ao entrar na moradia dos indivíduos que responderam ao formulário, o que se encontra em nada lembra a casa de um empresário bem sucedido.

\footnotetext{
"só prejuízo, perdi o emprego, gastei o que não tinha com advogado".

"com o crime só consegui cadeia, preconceito, fama de bandido perigoso. Tanto que mesmo, após anos sem voltar ao crime, ainda sou procurado pela polícia quando ocorre algum crime grande".
}

Por outro lado, porém, mesmo para os que responderam que os resultados da ação criminosa valeram a pena quanto ao retorno financeiro ao se deter a analisar seus pertences materiais, se vê que tais respostas são contraditórias. Pois, um dos sujeitos que respondeu que valeu a pena a ação criminosa, já que na época podia dar tudo que sua família necessitava, após cumprir cerca de vinte anos de cadeia entre entradas e saídas do sistema prisional e que hoje trabalha como telemoto, informou, durante o transcorrer da conversa, que não pôde dar uma festa de quinze anos para a filha, já que estava preso e não possuía condições financeiras para tanto.

Econ. e Desenv., Santa Maria, vol. 27, n.2, p. 308 - 325, jul. - dez. 2015 RE\&D 
Além disso, setenta e cinco por cento dos entrevistados afirmou que não costumava guardar parte do dinheiro obtido com a criminalidade. Já, dos vinte e cinco por cento que afirmaram guardar dinheiro para se prevenir quanto ao futuro, em muitos casos, segundo os mesmos, tal reserva se acaba rapidamente, pois estando preso, a família precisava pagar advogados, aluguel da residência, se alimentar e etc.

Assim, com base nas respostas ao formulário, pode se concluir que, embora grandes atacadistas do mercado de drogas ilícitas e realizadores de rentáveis assaltos milionários possam ser comparados a grandes empresários; porém, a maioria dos sujeitos que abarrotam o sistema carcerário brasileiro não costuma ter dinheiro sequer para financiar de maneira adequada sua defesa e, muitas vezes, sequer possui uma moradia com o mínimo de conforto, vivendo, muitas vezes, em condições mais insalubres que o mais humilde dos trabalhadores dos setores legais da economia.

\section{Considerações finais}

As respostas ao formulário forneceram elementos para a percepção de que, em geral, as pessoas entrevistadas que cumpriram pena de reclusão em Santa Maria eram, em sua primeira entrada no sistema carcerário, muito jovens e imaturas, de baixíssima escolaridade e usuárias de drogas ilícitas.

Em relação aos motivos que as levaram a cometer os delitos pelos quais foram presas ocorre uma diferença entre as respostas masculinas e femininas. Na percepção dos homens, foi a busca por status a motivação principal. Quanto às mulheres, a necessidade de sustentar à família, já que com os companheiros presos, as mesmas acabavam assumindo suas funções.

Tais pessoas, embora tendo consciência do risco que corriam, ao cometer os delitos não costumavam comparar o quanto poderiam vir a receber no mercado legal vis a vis com o que faturavam com a atividade delituosa. O perfil das pessoas acima relatado derruba por terra $\mathrm{o}$ principal pressuposto da Teoria Econômica do Crime, de que o sujeito que comete crimes econômicos pode ser considerado como um "empresário" dotado de uma fria racionalidade, capaz de analisar os diversos fatores envolvidos na tomada de decisão frente a adotar ou não o caminho da ilegalidade com o objetivo de maximizar lucros.

Conforme apurado no transcorrer da pesquisa, muitas das pessoas analisadas cometiam os crimes porque os meios para cometê-los estavam facilmente disponíveis (corroborando a Teoria das Oportunidades). E, também, segundo elas, porque tal caminho era, senão o único, pelo menos o mais fácil de obter uma boa renda, já que muitas estavam desempregadas, subempregadas e/ou não possuíam o mínimo de qualificação profissional para obter uma colocação no mercado formal de trabalho (corroborando os pressupostos da Teoria Neomarxista).

Com esta pesquisa ficou latente o fato de que para muitos jovens, e na maioria dos casos analisados os primeiros delitos ocorreram em uma idade bastante tenra, o desejo de deixar de ser invisível em uma sociedade que cultua o consumismo como representação de felicidade é tão irresistível, que para atingir tal objetivo, vale qualquer coisa.

Assim, restou confirmada a hipótese de pesquisa de que, muito mais do que apenas a questão econômica, a qual representa a aparência dos delitos que envolvem ganhos financeiros, fatores familiares, sociais e, até mesmo, aspectos psicológicos estão na essência do fenômeno da criminalidade. Ou seja, para tentar entender o que leva as pessoas à delinqüir é necessária a conjugação dos pressupostos tanto da Teoria Econômica do Crime, quanto das Oportunidades e 
da Neo-marxista, haja vista o ser humano ser muito mais complexo do que o frio e extremamente racional homo economicus da Economia tradicional.

REFERENCIAS

ABRAMOVAY, Miriam. Escola e Violências. Revista Observare. Volume 4. Outubro de 2008. Disponível em: $\quad$ file:///C:/Users/Usuarios/Downloads/escola e violencias _miriam_abramovay.pdf. Acesso em: 22 / 09 / 2015.

ANDRADE, E. L. Introdução à Pesquisa Operacional: Métodos e Modelos para Análise de Decisão. $2^{a}$ ed., LTC, Rio de Janeiro, 2000.

ARAÚJO, Jorge Luiz Medeiros e CARVALHO, Alcione da Costa. Violência, educação e exclusão social na região norte de Natal. Disponível em: http://webserver.falnatal.com.br/revista_nova/a6_v3/Artigo_violencia_ZN_\%20Direito.pdf.

Acesso em 22/09/2015.

BECKER, Gary. S. 1968. Crime and Punishment: An Economic Approach. Journal of Political Economy. Reprinted in Chicago Studies in Political Economy, edited by G.J.Stigler. Chicago and London: The University of Chicago Press, 1988.

BENTHAM, Jeremy. An Introduction to the Principles of Morals and Legislation. Oxford, 1907 reprint of 1823 edition. (First printed 1780.). Disponível em:

http://www.econlib.org/library/Bentham/bnthPML1.html. Acesso em 22/09/2015.

BRITTO, Tatiana A. Desemprego e crime: uma análise de séries de tempo para o Distrito Federal: 1992 a 1996. Brasília: Dissertação (Mestrado), 46 p. Departamento de Economia universidade de Brasília, 1999.

CARREIRA-FERNANDEZ, José; PEREIRA, Rogério. A criminalidade na região policial da grande São Paulo sob a ótica da economia do crime. Revista Econômica do Nordeste, Fortaleza: n. especial, p.898-918, 2000.

CHALMERS, Alan F.O que é Ciência Afinal. 1. ed. São Paulo: Brasiliense, 1993.

COHEN, Lawrence, FELSON, Marcus e LAND, Kenneth C. (1980), "Property crime rates in the United States: a macrodynamic analysis, 1947-1977". American Journal of Sociology, 86, 1: $90-119$.

COSTA, Fernando Nogueira da. Comportamentos dos investidores: do homo economicus ao homo pragmaticus. IE/UNICAMP, n. 165, ago. 2009.

COUTINHO, Raquel Z. A carne é fraca: religião, religiosidade e iniciação sexual entre estudantes do Ensino Médio na Região Metropolitana de Belo Horizonte, 2008. Dissertação apresentada ao curso de Pós-Graduação em Demografia do Centro de Desenvolvimento e Planejamento Regional da Faculdade de Ciências Econômicas da Universidade Federal de Minas Gerais, 2011.

CUNHA, Vagner Silva da. A proposta neoliberal no combate à criminalidade: o programa estadunidense tolerância zero. Revista de Estudos Sociais - ano 10, n. 19, v. 1, 2008.

DAHRENDORF, R. Law and Order. London: Stevens \& Sons, 1985.

DELLASOPPA, Emílio E. Fortuna et sapientia: o conceito de risco na reflexão teórica recente. Rio de Janeiro: UERJ, 2008.

Econ. e Desenv., Santa Maria, vol. 27, n.2, p. 308 - 325, jul. - dez. 2015 RE\&D 
FRINHANI, Fernanda de Magalhães Dias; SOUZA, Lídio de. Mulheres encarceradas e espaço prisional: uma análise de representações sociais.Rev. Psicologia v.7/n.1, 2005.

FRONER, Ricardo Pastre. A teoria econômica do crime: o roubo bancário. Trabalho de conclusão de curso, Faculdade de Ciências Econômicas UFRGS, 2008. Disponível em: http://www.lume.ufrgs.br/bitstream/handle/10183/16268/000666411.pdf?sequence=1.

GOMES, Fábio Guedes. Conflito social e welfarestate: Estado e desenvolvimento social no Brasil. RAP Rio de Janeiro 40 (2):201-36, Mar./Abr. 2006. Disponível em: http://www.scielo.br/pdf/rap/v40n2/v40n2a03.pdf. Acesso em 22/09/2015.

HASSON. M. E; MELEIRO. A. M. A. S. Reflexões sobre a desestruturação familiar e a criminalidade. In: RIGONATTI, S. P. (Coord.). Temas em Psiquiatria Forense e Psicologia Jurídica. São Paulo: Vetor, 2003. p. 79-104.

KAHN, Túlio. Cidades Blindadas - ensaios de criminologia. Conjuntura Criminal, São Paulo, 2001.

MERTON, R. K. Social structure and anomie. Social Theory and Social Structure, rev. Ed. New York, Free Press, 1957.

MORAES JR, Martim Cabeleira. A violência das (e contra as) policias do Estado do

Rio Grande do Sul. Dissertação apresentada ao programa de mestrado em Sociologia, da Universidade Federal do Rio Grande do Sul (UFRGS), Porto Alegre, 2005.

OLIVEIRA, Cristiano Aguiar. Criminalidade e o tamanho das cidades brasileiras: um enfoque da Economia do Crime. Anais do XXXIII Encontro Nacional de Economia. ANPEC Associação Nacional dos Centros de Pós Graduação em Economia, 2005.

PINDICK, Robert; RUBINFELD, Daniel L. Microeconomia. 5 ed. São Paulo: Prentice Hall, 2002.

SAPORI, L. F.; WANDERLEY, C. B. A relação entre desemprego e violência na sociedade brasileira: entre o mito e a realidade. Konrad Adenauer Stiftung. A violência do cotidiano. São Paulo: Cadernos Adenauer, ano II, n. 1, 2001.

SCHAEFER, Gilberto; SHIKIDA, Peri A.F. Economia do crime: elementos teóricos e evidências empíricas. Revista de Análise Econômica/UFRGS, edição 36, ano 19, setembro de 2001.

SCOTTI, Ricardo Jefferson. Finanças comportamentais no Brasil. São Paulo, FAAP, 2007, 70p.

SILVA, Claudia Gabriele da. A criminalidade enquanto expressão da questão social: a realidade socioeconômica das apenadas do complexo penal Dr. João Chaves. III JORNADA INTERNACIONAL DE POLÍTICAS PÚBLICAS São Luís - MA, 28 a 30 de agosto 2007. SIMEÃO, Francisco. Desemprego e criminalidade: redução da jornada amplia postos de trabalho e diminui marginalidade. Revista FAE BUSINESS, número 8 maio 2004.

SMITH, Adam. A riqueza das nações: investigação sobre sua natureza e suas causas. São Paulo: Nova Cultural, 1996.v.1.

RE\&D Econ. e Desenv., Santa Maria, vol. 27, n.2, p. 308 - 325, jul. - dez. 2015 
VIAPIANA, Luiz Tadeu. Economia do crime: uma explicação para a formação do criminoso. Editora AGE Ltda. 2006.

ZALUAR, Alba. Da revolta ao crime. São Paulo: Moderna, 1997.

Econ. e Desenv., Santa Maria, vol. 27, n.2, p. 308 - 325, jul. - dez. 2015 RE\&D 